\title{
Dessecação química para antecipação de colheita em cultivares de soja
}

\section{Chemical desiccatin for early harvest in soybean cultivars}

\author{
Tamara Pereira ${ }^{1}$; Cileide Maria Medeiros Coelho ${ }^{2 *}$; Clovis Arruda Souza ${ }^{3}$; \\ Analu Mantovani ${ }^{4}$; Vanderléia Mathias ${ }^{5}$
}

\begin{abstract}
Resumo
O uso de dessecantes é uma alternativa para antecipar a colheita de soja e manter a qualidade fisiológica das sementes. O objetivo deste trabalho foi avaliar o desempenho produtivo e a germinação de sementes em resposta a diferentes épocas e produtos químicos para dessecação e antecipação da colheita de cultivares de soja. O experimento foi conduzido em Campos Novos, em duas safras agrícolas sob o delineamento em blocos casualizados, dispostos em parcelas sub-subdivididas. Na parcela foram testados dois estádios fenológicos de aplicação (R7.1 e R7.3), nas subparcelas cinco cultivares de soja (NA 5909 RG, CD 2585 RR, BMX Turbo RR, SYN 1059 RR e BENSO 1RR e na sub-subparcela foram aplicados três dessecantes (glufosinato de amônio, paraquat e carfentrazone na safra 2011/12) e uma testemunha. Na safra 2012/13 o carfentrazone foi substituído pelo diquat. Foi avaliado o número de dias de antecipação da colheita, a produtividade de sementes, o número de vagens por planta, o número de sementes por vagem, a massa de 100 sementes e a germinação. A dessecação química com o uso de glufosinato de amônio e paraquat aplicados no estádio R7.1 permitiu antecipar a colheita em seis dias (safra 2011/12) e proporcionou a manutenção do percentual de germinação $(90 \%$ e $92 \%$ ) em comparação a testemunha (76\%). A dessecação não influenciou negativamente a produtividade de sementes, mas reduziu a massa de sementes nas duas safras agrícolas, e a antecipação da colheita foi dependente da ausência de chuva na pré-colheita. Os dessecantes podem ser usados na antecipação de colheita em campos de produção de sementes de soja.
\end{abstract}

Palavras-chave: Glicine max, maturidade fisiológica, herbicida, germinação

\begin{abstract}
The use of desiccants is an alternative to anticipate the soybean harvest and keep the physiological quality of seed. The objective of this work was to assess the production performance and germination seeds in response to differents stages and desiccation chemicals products to early harvest of soybean cultivars. The experiment was conducted in Campos Novos, in two harvests, it was used a randomized complete block design disposed in split-split-plots. Two phonological stages of application (stage R7.1 and R7.3) were tested in the main plot. Five soybean cultivars (NA 5909 RG, CD 2585 RR, BMX Turbo RR, SYN 1059 RR and BENSO 1RR were evaluated in the subplots, and three desiccants ammonium glufosinate, paraquat, carfentrazone-ethyl in the 2011/12 season and one control (without the desiccant application) were evaluated in the sub-subplots. In the 2012/13 season the carfentrazone-ethyl was

1 Eng $^{\mathrm{a}}$ Agr $^{\mathrm{a}}$, Dr $^{\mathrm{a}}$ em Produção Vegetal, Dept ${ }^{\mathrm{o}}$ de Fitotecnia, Universidade do Oeste de Santa Catarina, UNOESC, Campos Novos, SC. E-mail: tamara.pereira@unoesc.edu.br

2 Eng $^{\mathrm{a}}$ Agr $^{\mathrm{a}}$, Dr ${ }^{\mathrm{a}}$ em Ciências, Dept ${ }^{\circ}$ de Agronomia, Universidade do Estado de Santa Catarina, UDESC, Lages, SC. E-mail: cileide.souza@udesc.br; cileidecoelho@yahoo.com.br

3 Eng $^{\circ} \mathrm{Agr}^{\circ}$, Dr. em Ciências: Produção Vegetal, Dept ${ }^{\circ}$ de Agronomia, UDESC, Lages, SC. E-mail: souza_clovis@yahoo.com.br

4 Enga Agr ${ }^{\mathrm{a}}, \mathrm{Dr}^{\mathrm{a}}$ em Ciência do Solo, Dept ${ }^{\mathrm{o}}$ de Solos, UNOESC, Campos Novos, SC. E-mail: analu.mantovani@unoesc.edu.br

5 Enga Agra , UNOESC, Campos Novos, SC. E-mail: vanderleia.mathias@gmail.com
\end{abstract}

Autor para correspondência 
substituted by diquat. It were evaluated the number of the days in the early harvest, yield, number of pods per plant, number of seeds per pod, mass of 100 seeds and germination percentage. The chemical dessecation with the use of glufosinate ammonium and paraquat applied in R7.1 stadium allowed to anticipate the harvest in six days $(2011 / 12)$ and provided maintenance germination percentage $(90 \%$ and $92 \%$ ) compared to control (76\%). The dessecation didn't influence negatively on seeds productivity, but reduced the mass of seeds in the two grown season, and early harvest was dependent of pre-harvest rain absence, with this preamble. The use of dessicants is a possibility of early harvest in production field of soybean seeds.

Key words: Glicine max, physiological maturity, herbicide, germination

\section{Introdução}

O estado de Santa Catarina na safra 2013/14 produziu aproximadamente 200 mil toneladas de sementes de soja, o que representa em torno de $7 \%$ da produção brasileira. A região meio-oeste vem ganhando espaço no cenário de produção estadual de sementes de soja e estima-se que o município de Campos Novos produza em torno de 80 mil toneladas de semente de soja por safra, o que representa aproximadamente $40 \%$ da produção de sementes de soja do estado (APROSESC, 2014).

A produção de sementes, de elevada qualidade, depende da utilização de técnicas de manejo diferenciadas para superar algumas limitações impostas por fatores climáticos, nutricionais, danos causados por insetos e micro-organismos que podem reduzir a qualidade das sementes (FRANÇA NETO et al., 2007). No caso das sementes de soja, o retardamento da colheita após a maturação fisiológica constitui uma das principais causas da redução da germinação e vigor (SEDYAMA, 2013).

Dentre as diversas práticas de manejo adotadas para obtenção de sementes de qualidade, a dessecação pré-colheita é uma alternativa. Segundo o departamento técnico das cooperativas de Campos Novos aproximadamente 5\% dos produtores de soja do município adotam a dessecação pré-colheita como alternativa para minimizar o decréscimo na qualidade das sementes no campo antecipando a colheita. Esta baixa percentagem possivelmente está relacionada à ausência de trabalhos que indiquem viabilidade do uso desta técnica em Santa Catarina.
A prática de dessecação tem como objetivo promover rápida secagem das plantas e melhorar a uniformidade de maturação, e consequentemente antecipar a colheita (INOUE et al., 2003). Para ter êxito no uso de dessecantes é necessário estudar as respostas das cultivares para a condição de clima da região específica de produção, e também a sua relação com o tipo de dessecante, estádio de aplicação, o que podem influenciar diretamente na eficiência de ação do produto e indiretamente sobre os aspectos de produtividade e qualidade de sementes produzidas.

Neste aspecto, existem relatos divergentes na literatura comrelaçãoaouso dosherbicidas (paraquat, diquat, glufosinato de amônio e carfentrazone) como dessecantes em pré-colheita e sua influência nos componentes de produção e qualidade de sementes. Segundo Guimarães et al. (2012) a dessecação de plantas de soja em pré-colheita com os herbicidas glufosinato de amônio, paraquat e glyphosate nos diferentes estádios fenológicos (R6, R7.2 e R8.1) não afetou a produtividade de sementes. $\mathrm{O}$ uso do herbicida paraquat promoveu os melhores índices de germinação e vigor quando utilizado nos estádios R6 e R7.2; de forma contrária o herbicida glyphosate reduziu o vigor de sementes.

No entanto, o uso de dessecantes pode reduzir a produtividade e a qualidade de sementes, conforme Lamego et al. (2013) os quais observaram que a aplicação de paraquat no estádio R6.0 e R7.1 reduziu em 35 e 13\% a produtividade de sementes da cultura. Além disso, as sementes oriundas da dessecação no estádio R6.0 apresentaram menor vigor de plântulas. 
Possivelmente, a principal explicação para as variações nos resultados de qualidade fisiológica e na produtividade de sementes, em função da dessecação pré-colheita pode estar associado ao tipo de dessecante, dose e época de aplicação do produto. Épocas de aplicação do produto coincidentes com período pós-maturação fisiológica, evitam perdas de produtividade (PELÚZIO et al., 2008) e alteração de qualidade das sementes (GUIMARÃES et al., 2012). Herbicidas utilizados durante a dessecação pré-colheita podem deixar resíduos nas sementes e o mesmo causar redução da germinação (TOLEDO; CAVARIANI; FRANÇA-NETO, 2012).

Em função da ausência de trabalhos com uso de dessecantes em pré-colheita no meio oeste de Santa Catarina, o objetivo deste trabalho foi avaliar o desempenho produtivo e a germinação de sementes em resposta a diferentes épocas e produtos químicos para dessecação e antecipação da colheita de cultivares de soja.

\section{Material e Métodos}

$\mathrm{O}$ experimento foi realizado em condições de campo, nas safras 2011/12 e 2012/13, no município de Campos Novos - SC, com coordenadas geográficas $24^{\circ} 24^{\prime}$ de longitude sul e $51^{\circ} 13^{\prime}$ de longitude oeste, com aproximadamente $925 \mathrm{~m}$ de altitude, $17^{\circ} \mathrm{C}$ de temperatura média anual e 1800 mm de precipitação média anual (DUFLOTH et al., 2005).

O delineamento experimental utilizado foi de blocos ao acaso, dispostos em parcelas subsubdivididas, com quatro repetições. Nas parcelas ( 25 X 39 m), avaliaram-se dois estádios fenológicos de aplicação: estádio R7.1 (maturidade fisiológica - inicio a $50 \%$ de amarelecimento de folhas e vagens), estádio R7.3 (mais de 75\% das folhas e vagens amarelas). Em cada estádio fenológico de aplicação, foram avaliadas, nas subparcelas (13 x 5,0 m), cinco cultivares de soja (NA 5909 RG, CD 2585 RR, BMX Turbo RR, SYN 1059 RR e BENSO $1 R R)$ e nas sub-subparcelas $(8,6 \times 5,0 \mathrm{~m})$ foram aplicados os dessecantes Glufosinato de amônio (Finale), Paraquat (Gramoxone), Carfentrazone (Aurora) (safra 2011/12) e uma testemunha (sem aplicação de dessecante). Na safra 2012/13 o herbicida carfentrazone foi substituído pelo diquat (Reglone).

A semeadura foi realizada no dia 24 de outubro de 2011 (safra 2011/12) e 01 dezembro de 2012 (safra 2012/13), sob sistema de plantio direto, tendo aveia branca como cultura antecessora. Foram utilizadas 13 sementes aptas por metro linear, propiciando uma densidade de 260.000 plantas por hectare. A adubação realizada no momento da semeadura para a safra 2011/12 foi $6,8 \mathrm{~kg}$ de Nitrogênio, 17 $\mathrm{Kg}$ de $\mathrm{P}_{2} \mathrm{O}_{5}$ e $13,6 \mathrm{~kg}$ de $\mathrm{K}_{2} \mathrm{O}$ por hectare, baseada na análise do solo (pH: 5,6; potássio: $324 \mathrm{mg} \mathrm{dm}{ }^{-}$ 3; fósforo: $15,3 \mathrm{mg} \mathrm{dm}^{-3}$ e matéria orgânica: $12,4 \mathrm{~g}$ $\left.\mathrm{kg}^{-1}\right)$. Na safra 2012/13 foram $8 \mathrm{~kg}$ de Nitrogênio, $96 \mathrm{Kg}$ de $\mathrm{P}_{2} \mathrm{O}_{5}$ e $48 \mathrm{~kg} \mathrm{~K}_{2} \mathrm{O}$ por hectare, baseada na análise de solo ( $\mathrm{pH}$ : 6,0; potássio: $105 \mathrm{mg} \mathrm{dm}^{-3}$; fósforo: $17 \mathrm{mg} \mathrm{dm}^{-3}$ e matéria orgânica: $40 \mathrm{~g} \mathrm{~kg}^{-}$ $\left.{ }^{1}\right)$ safra 2012/13. Os dados diários de precipitação pluvial e temperatura para o local de cultivo foram obtidos junto a Estação Experimental da Epagri Campos Novos (EPAGRI/CIRAM, 2013), a qual fica localizada a $5 \mathrm{Km}$ de distancia do local do experimento (Figura 1).

Para a identificação dos estádios fenológicos de desenvolvimento utilizou-se a escala de Ritchie, Hanway e Thompson (1982) citado por Sedyama (2013) e o teor de água das sementes (MARCOS FILHO, 2005). O teor de água das sementes foi verificado através do método da estufa a $105^{\circ} \mathrm{C}$ (BRASIL, 2009). As aplicações dos dessecantes foram realizadas em: 16/03/2012 (safra 2011/12) e 28/02/2013 (safra 2012/13) (estádio R7.1 - maturidade fisiológica - inicio a $50 \%$ de amarelecimento de folhas e vagens), teor de água em torno de 50\% (safra 2011/12) e 60\% (safra 2012/13) e 28/03/2012 (safra 2011/12) e 14/03/2013 (safra 2012/13) (estádio R7.3 - mais de 75\% das folhas e vagens amarelas) teor de água em torno de $25 \%$ (safra 2011/12) e 30\% (safra 2012/13). 
Figura 1. Precipitação pluvial $24 \mathrm{~h}(\mathrm{~mm})$ e temperatura média $\left({ }^{\circ} \mathrm{C}\right)$ registradas nas safras 2011/12 e 2012/13, correspondente ao período de maturidade fisiológica (estádio R7.1) até a colheita das plantas de soja, em Campos Novos, SC.

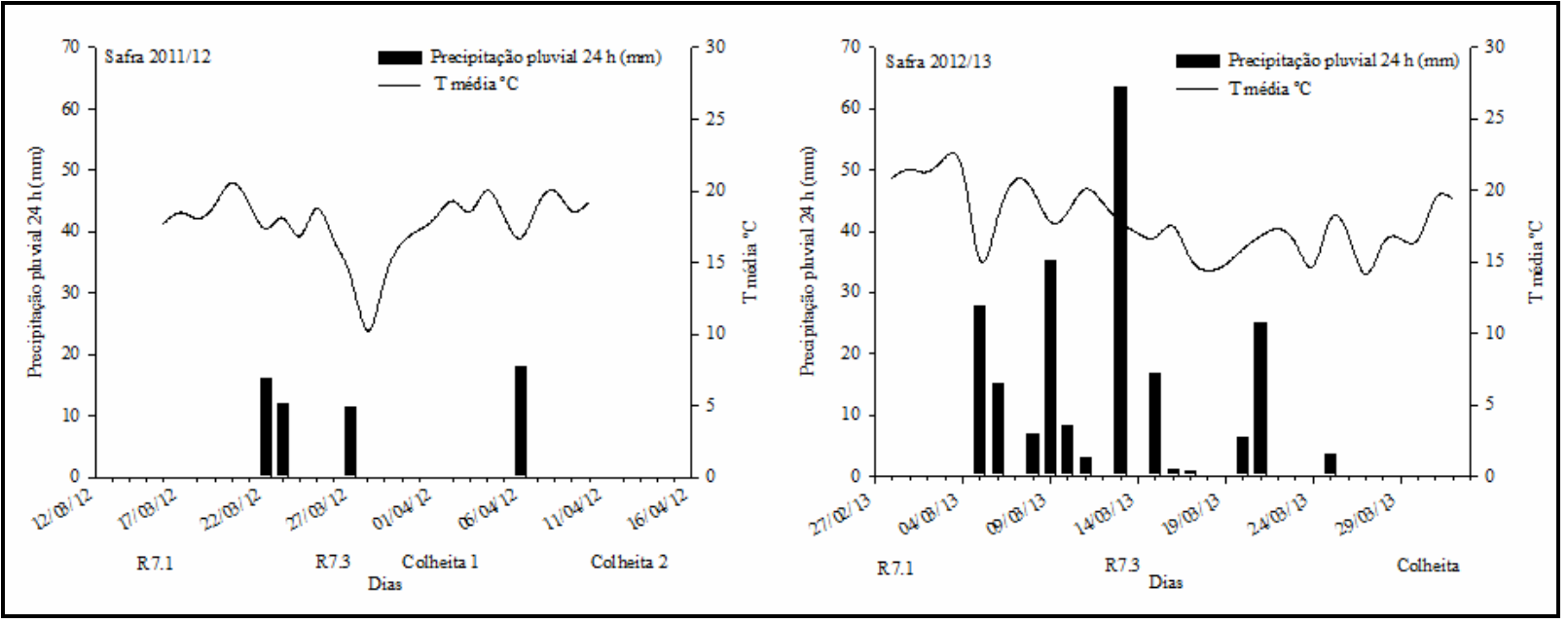

Colheita 1: Colheita das parcelas tratadas com os dessecantes glufosinato de amônio e paraquat aplicados no estádio R7.1 da safra 2011/12, Colheita 2: Colheita das parcelas tratadas com o dessecante carfentrazone aplicados no estádio R7.1 da safra 2011/12, e de todos os dessecantes aplicados no estádio R7.3 e a testemunha.

Colheita: colheita de todos os tratamentos da safra 2012/13.

Fonte: Elaboração dos autores.

A aplicação dos herbicidas (dessecantes) foi realizada no período da manhã, com um pulverizador mecanizado, com vazão de $300 \mathrm{~L}$ ha-1 e ponta tipo leque vazão $1,63 \mathrm{~L} \mathrm{~min}^{-1}$ e ângulo de $110^{\circ}$. No processo de aplicação do dessecante foram utilizadas 2 secções da barra de pulverização, totalizando 8,6 m de comprimento. Os dessecantes utilizados foram o glufosinato de amônio $\left(2,0 \mathrm{~L} \mathrm{ha}^{-1}\right.$ $+0,2 \%$ de Hoefix ${ }^{\circledR}$ - espalhante adesivo); paraquat $\left(2,0 \mathrm{~L} \mathrm{ha}^{-1}\right)$, carfentrazone $\left(125 \mathrm{~mL} \mathrm{ha}^{-1}+0,5 \%\right.$ de óleo mineral) e diquat $\left(2,0 \mathrm{~L} \mathrm{ha}^{-1}\right)$.

Realizou-se a coleta de 10 plantas aleatoriamente da área útil da parcela antes da colheita para a avaliação dos componentes de produção: número de vagens por planta, número de sementes por vagem e massa de 100 sementes.

A colheita foi manual e na debulha das vagens utilizou-se uma trilhadora estacionária. O critério utilizado para colheita das parcelas foi baseado no monitoramento de características visuais de amadurecimento das plantas e no teor de água das sementes (13-15\% em base úmida), através da coleta de vagens de 10 plantas da bordadura das parcelas e quantificação do teor de água em estufa $105^{\circ} \mathrm{C}$ $\left( \pm 5^{\circ} \mathrm{C}\right)$ (BRASIL, 2009). A colheita ocorreu em 03/04/2013 - estádio R7.1, dessecantes: glufosinato de amônio e paraquat; 10/04/2013 - estágio R7.1, dessecante: carfentrazone; estágio R7.3, para todos os dessecantes e testemunha para a safra 2011/12. Já na safra 2012/13 a colheita realizou-se na data de 01/04/2013 para todos os tratamentos.

Para avaliação da germinação as sementes foram padronizadas para umidade de $13 \%$, em seguida foram selecionadas em peneira mínima de $6,5 \mathrm{~mm}$, retirando-se uma amostra média de $2 \mathrm{~kg}$, de onde foi obtida a amostra de trabalho (BRASIL, 2009) as quais foram utilizadas para o teste de germinação.

O percentual de germinação foi realizado com 4 subamostras de 50 sementes de cada tratamento, distribuídas em papel germiteste e colocadas para germinar a $25^{\circ} \mathrm{C}$, seguindo as recomendações das Regras de Análise de Sementes (RAS) (BRASIL, 2009). 
Os dados foram submetidos ao teste de Shapiro Wilk (5\%) para verificar se seguiram a distribuição normal e de Cochran e Barlett (5\%) para verificar a homogeneidade de variâncias. Os dados de percentual de germinação foram transformados em arco seno de $(\mathrm{x} / 100)^{0,5}$. A análise de variância foi realizada pelo teste $\mathrm{F}$ a $5 \%$ de significância, na presença de interação significativa procederam-se os desdobramentos necessários. As médias foram comparadas pelo teste Tukey a 5\% de significância.

\section{Resultados e Discussão}

Com relação aos componentes de produção e a produtividade média a safra 2011/12 apresentou maior produtividade de sementes $(3366 \mathrm{~kg}$ ha$\left.{ }^{1}\right)$ do que a safra 2012/13 (Tabela 1) e, o que contribuiu para isto foi número de vagens por planta (76) e a massa de 100 sementes (18 g), as quais também foram superiores na safra 2011/12 (Tabela 1). Segundo Dalchiavon e Carvalho (2012) o número de vagens por planta e a massa de sementes por planta possuem correlação direta com a produtividade da soja. Estes componentes do rendimento podem também ser influenciados pelas técnicas de manejo adotadas, condições climáticas do ambiente de cultivo e potencial produtivo da cultivar (MUNDSTOCK; THOMAS, 2005).

A produtividade de sementes da safra 2011/12 foi superior para o tratamento oriundo da dessecação pré-colheita realizada no estádio R7.1 com o uso dos dessecantes paraquat e glufosinato de amônio para as cultivares NA5909 RG, SYN 1059 RR E BMX Turbo RR (Tabela 2). Isto pode ocorrido, pois a aplicação dos herbicidas paraquat e glufosinato de amônio no estádio R7.1 antecipou a colheita em seis dias. Além disso, as plantas oriundas da aplicação de carfentrazone e da testemunha permaneceram por mais tempo no campo, o que pode ter favorecido a deiscência de vagens e consequentemente a menor produtividade (Tabela 2). Corrêa (2012) encontrou maior produtividade de sementes na cultivar NS4823 oriundas da dessecação com o glufosinato de amônio quando comparado a testemunha, e explica que isto pode estar associado a menor respiração das sementes oriundas da dessecação. No estádio R7.3 observou-se que a testemunha apresentou as menores produtividades comparada aos dessecantes utilizados, com exceção da cultivar CD2585 RR (Tabela 2).

Os resultados de produtividade da safra 2012/13 demonstraram efeito significativo apenas para cultivar (Tabela 1), onde a cultivar BMX Turbo RR, juntamente com a SYN 1059 RR apresentaram as maiores produtividades (2833 e $2896 \mathrm{~kg} \mathrm{ha}^{-1}$ ) e a Benso 1RR apresentou a menor produtividade (2034 $\left.\mathrm{kg} \mathrm{ha}^{1}\right)$. Fica evidenciado portanto, que o potencial produtivo é determinado pelo material genético utilizado e que a dessecação pré-colheita realizada na safra 2012/13 não alterou a produtividade em função do uso dos dessecantes paraquat, diquat e glufosinato de amônio e do estádio de aplicação do produto (Tabela 1). Isto demonstra que a partir do estádio R7.1 (maturidade fisiológica) as sementes já acumularam quantidades consideráveis de matéria seca assegurando que a produtividade de sementes não seja alterada negativamente. Inoue et al. (2012), encontraram resultados com este mesmo comportamento aplicando dessecantes a partir do estádio R7.5 (após a maturidade fisiológica). Porém, Daltro et al. (2010) e Guimarães et al. (2012), verificaram que o uso da dessecação química mesmo antes da maturidade fisiológica (estádios de desenvolvimento R6.0 ou R6.5) com o uso dos dessecantes paraquat ou diquat e paraquat e glufosinato de amônio também não afetam a produtividade da soja. 
Tabela 1. Resultado da análise de variância (quadrado médio) dos componentes de produção e germinação de sementes das safras 2011/12 e 2012/13 de 05 cultivares de soja, 03 dessecantes em 02 estádios fenológicos de aplicação de herbicidas, no município de Campos Novos, SC.

\begin{tabular}{|c|c|c|c|c|c|c|}
\hline \multicolumn{7}{|c|}{ Safra 2011/12 } \\
\hline $\mathrm{CV}$ & GL & NVP & NSV & M100 (g) & PROD $\left(\mathrm{kg} \mathrm{ha}^{-1}\right)$ & G (\%) \\
\hline Bloco & 3 & 278,4 & 0,04 & 1,8 & $745273,7^{*}$ & 0,01 \\
\hline Estádio (E) & 1 & 873,1 & $0,22 *$ & 0,4 & $3503120,2^{*}$ & 0,02 \\
\hline Erro a & 3 & 134,8 & 0,01 & 0,4 & 48160,1 & 0,003 \\
\hline Parcelas & 7 & - & - & - & - & - \\
\hline $\mathrm{CV}(\mathrm{a})$ & - & 16,8 & 5,7 & 3,4 & 6,5 & 5,2 \\
\hline Cultivar (C) & 4 & $1999,4^{*}$ & $0,17^{*}$ & $88,5^{*}$ & 203154,2 & $0,03 *$ \\
\hline E X C & 4 & 46,6 & 0,01 & 0,7 & $545690,9 *$ & 0,002 \\
\hline Erro b & 24 & 139,7 & 0,01 & 1,6 & 109231,8 & 0,005 \\
\hline SubP & 39 & - & - & - & - & - \\
\hline CV (b) & - & 17,1 & 5,7 & 7,0 & 9,8 & 6,2 \\
\hline Dessecante (D) & 3 & $507,9^{*}$ & 0,01 & $7,2 *$ & $3960153,0^{*}$ & $0,4^{*}$ \\
\hline E X D & 3 & 324,3 & 0,02 & $5,3 *$ & $136944,4 *$ & $0,1^{*}$ \\
\hline CX D & 12 & 164,3 & 0,03 & $2,3^{*}$ & $310577,2 *$ & $0,03 *$ \\
\hline EX C X D & 12 & 180,8 & 0,02 & 0,5 & $353699,7 *$ & 0,01 \\
\hline Erro c & 90 & 132,9 & 0,02 & 0,6 & 80290,1 & 0,006 \\
\hline $\mathrm{CV}(\mathrm{c})$ & - & 16,7 & 6,7 & 4,3 & 8,4 & 6,6 \\
\hline Total & 159 & - & - & - & - & - \\
\hline Média & - & 76 & 2,5 & 18 & 3366 & 83 \\
\hline \multicolumn{7}{|c|}{ Safra 2012/13 } \\
\hline $\mathrm{CV}$ & GL & NVP & NSV & M100 (g) & PROD $\left(\mathrm{kg} \mathrm{ha}^{-1}\right)$ & $\mathrm{G}(\%)$ \\
\hline Bloco & 3 & 18,1 & $0,02 *$ & 0,22 & 62722,2 & 0,002 \\
\hline Estádio (E) & 1 & 84,4 & 0,01 & $31,7^{*}$ & 127051,7 & 0,007 \\
\hline Erro a & 3 & 28,4 & 0,0001 & 0,27 & 698192,0 & 0,009 \\
\hline Parcelas & 7 & - & - & - & - & - \\
\hline CV (a) & - & 17 & 1,5 & 3,3 & 32 & 8,1 \\
\hline Cultivar (C) & 4 & $676,1^{*}$ & $0,07 *$ & $18,0^{*}$ & $4863394,2^{*}$ & $0,05^{*}$ \\
\hline $\mathrm{EXC}$ & 4 & 7,6 & 0,0007 & $1,6^{*}$ & 192026,9 & $0,12 *$ \\
\hline Erro b & 24 & 14,6 & 0,01 & 0,3 & 195304,3 & 0,009 \\
\hline SubP & 39 & - & - & - & - & - \\
\hline $\mathrm{CV}(\mathrm{b})$ & - & 12 & 4,5 & 3,3 & 17 & 8,1 \\
\hline Dessecante (D) & 3 & 11,9 & 0,01 & $6,0^{*}$ & 372345,4 & $0,02 *$ \\
\hline EX D & 3 & $114,9^{*}$ & 0,007 & $4,3^{*}$ & 386135,9 & 0,008 \\
\hline CX D & 12 & 23,7 & 0,02 & $0,9 *$ & 184950,1 & $0,03 *$ \\
\hline EX CX D & 12 & 12,1 & 0,009 & $0,7^{*}$ & 100086,7 & $0,02 *$ \\
\hline Erro c & 90 & 14,9 & 0,02 & 0,3 & 205677,3 & 0,005 \\
\hline $\mathrm{CV}(\mathrm{c})$ & - & 12 & 5,0 & 3,5 & 17 & 5,8 \\
\hline Total & 159 & - & - & - & - & - \\
\hline Média & - & 31 & 2,5 & 15 & 2561 & 85 \\
\hline
\end{tabular}

CV: Causa de Variação; SubP: subparcelas; D: dessecantes; NVP: número de vagens por planta; NSV: número de sementes por vagem; M100: massa de 100 sementes; PROD: produtividade de sementes; G: percentual de germinação; CV: coeficiente de variação.

*significativo pelo teste $\mathrm{F}$ a $5 \%$ de probabilidade de erro.

Fonte: Elaboração dos autores. 
Tabela 2. Produtividade de sementes de cultivares de soja em função da aplicação de diferentes dessecantes em cada estádio fenológico na safra 2011/12, do município de Campos Novos, SC.

\begin{tabular}{ccccc}
\hline & \multicolumn{4}{c}{ Estádio Fenológico R 7.1 } \\
\hline & \multicolumn{4}{c}{ Dessecantes } \\
\cline { 2 - 5 } Cultivares & Testemunha & Carfentrazone & Glufosinato de amônio & Paraquat \\
\cline { 2 - 5 } CD 2585 RR & B 3016 a & B 3106 b & B 3513 bc & A 4093 a \\
NA 5909 RG & C 2842 a & B 3403 ab & A 4021 ab & A 4210 a \\
BENSO 1RR & AB 3246 a & A 3705 a & B 3127 c & AB 3466 b \\
SYN 1059 RR & C 2686 a & B 3224 ab & A 4432 a & A 4234 a \\
BMX Turbo RR & B 2911 a & B 3243 ab & A 4031 ab & A 3931 a \\
\hline CD 2585 RR & A 3016 ab & A 3077 a & A 3124 b & A 3101 bc \\
NA 5909 RG & B 2842 ab & A 3418 a & AB 3252 b & A 3382 ab \\
BENSO 1RR & B 3246 a & AB 3448 a & A 3890 a & AB 3587 a \\
SYN 1059 RR & B 2686 b & A 3321 a & A 3313 b & AB 3184 abc \\
BMX Turbo RR & B 2911 ab & A 3488 a & AB 3358 b & B 2880 c \\
\hline
\end{tabular}

Médias seguidas pela mesma letra, maiúscula na linha (antecedida da média) e minúscula na coluna, não diferem entre si pelo teste Tukey, a 5\% de probabilidade de erro.

Fonte: Elaboração dos autores.

Na safra 2011/12 o número de vagens/planta e o número de sementes/vagem apresentaram diferenças entre os estádios fenológicos e as cultivares (Tabela 1). A aplicação dos dessecantes no estádio R7.1 proporcionou maior número de vagens/planta e sementes/vagem (71 vagens/planta e 2,4 sementes/ vagem) do que o estádio R7.3 (67 vagens/planta e 2,3 sementes/vagem), o que contribuiu para a maior produtividade oriundo do uso da dessecação no estádio R7.1. Acultivar Benso 1RR apresentou maior número de sementes/vagem (2,4 sementes) e maior número de vagens/planta (77 vagens). Segundo Souza et al. (2010) o número de vagens por planta e o número de sementes por vagem são componentes de produção que apresentam correlação significativa com o rendimento de sementes na cultura da soja.

O número de sementes/vagem dentre os componentes de produção é o componente primário que possui menor influencia das técnicas de manejo e condições climáticas durante o cultivo. Isto está relacionado a uniformidade construída no melhoramento genético para esta característica (MUNDSTOCK; THOMAS, 2005), a qual possui variabilidade entre as cultivares, como demonstrado pela cultivar Benso $1 \mathrm{RR}$ a qual manteve o maior número de sementes por vagem nas duas safras agrícolas.

Na safra 2012/13 o número de vagens por planta foi menor no estádio R7.1 em plantas dessecadas com o paraquat do que os demais herbicidas (Tabela 3). Este fato pode estar associado a rápida dessecação da planta oriunda da ação do paraquat, juntamente a permanência das plantas no campo, o que pode propiciar a deiscência (ROMAN et al., 2007) e posterior queda de vagens.

Analisando o desdobramento da interação estádio x dessecante para a massa de 100 sementes da safra 2011/12 observou-se que a mesma foi menor na dessecação com paraquat e glufosinato de amônio no estádio R7.1 quando comparado ao estádio R7.3 (Tabela 4). Este fato pode estar associado às sementes não terem totalmente atingido o final da fase III no estágio de desenvolvimento das sementes, onde ocorre o maior acúmulo de matéria seca (MARCOS FILHO, 2005). A rápida dessecação gerada pelos herbicidas aplicados na planta cessou o acúmulo de matéria seca que ainda estava atingido algumas sementes. 
Tabela 3. Número de Vagens/planta de cultivares de soja em função da aplicação de diferentes dessecantes em cada estádio fenológico na safra 2012/13, do município de Campos Novos, SC.

\begin{tabular}{ccccc}
\hline \multirow{2}{*}{ Estádio Fenológico } & \multicolumn{4}{c}{ Dessecantes } \\
\cline { 2 - 5 } & Testemunha & Glufosinato de amônio & Diquat & Paraquat \\
\hline R7.1 & A 31 a & A 34 a & A 33 a & B 29 b \\
R7.3 & A 31 a & A 29 b & A 30 a & A 32 a \\
\hline
\end{tabular}

Médias seguidas pela mesma letra, maiúscula na linha (antecedida da média) e minúscula na coluna, não diferem entre si pelo teste Tukey, a 5\% de probabilidade de erro.

Fonte: Elaboração dos autores.

Tabela 4. Massa de 100 sementes de cultivares de soja em função da aplicação de diferentes dessecantes em cada estádio fenológico na safra 2011/12, do município de Campos Novos, SC.

\begin{tabular}{|c|c|c|c|c|}
\hline \multirow[b]{2}{*}{ Estádio Fenológico } & \multicolumn{4}{|c|}{ Dessecantes } \\
\hline & Testemunha & Carfentrazone & Glufosinato de amônio & Paraquat \\
\hline R7.1 & A 18,4 a & A 18,9 a & B 17,4 b & B 17,3 b \\
\hline $\mathrm{R} 7.3$ & A 18,4 a & A $18,0 \mathrm{~b}$ & A 18,0 a & A $18,0 \mathrm{a}$ \\
\hline
\end{tabular}

Médias seguidas pela mesma letra, maiúscula na linha (antecedida da média) e minúscula na coluna, não diferem entre si pelo teste Tukey, a 5\% de probabilidade de erro.

Fonte: Elaboração dos autores.

Estes resultados foram similares aos encontrados por Inoue et al. (2012) os quais observaram redução da massa de 100 sementes com o uso da dessecação pré-colheita com diquat no estágio R6.5 e R7.0 quando comparado ao estádio R7.5 para a cultivar SYN 9074 RR. Em contrapartida, Pelúzio et al. (2008) não encontrou diferenças entre a massa de 100 sementes com a aplicação de paraquat nos estádios R6.0, R7.0 e R8.0 para a cultura da soja.
Considerando a interação cultivar $\mathrm{x}$ dessecante, observa-se que a cultivar BMX Turbo RR apresentou a maior massa de 100 sementes quando comparadas as demais cultivares no tratamento testemunha e em cada dessecante para a safra 2011/2012 e 2012/13 (Tabelas 5 e 6). Segundo Santos et al. (2012) e Pereira et al. (2009) a variável massa de 100 sementes é uma das característica que mais contribui com a diversidade genética, o que explica esta variação da massa em função das cultivares de soja.

Tabela 5. Massa de 100 sementes de cultivares de soja em função da aplicação de diferentes dessecantes na safra 2011/2012, do município de Campos Novos, SC.

\begin{tabular}{|c|c|c|c|c|}
\hline \multirow{2}{*}{ Cultivares } & \multicolumn{4}{|c|}{ Dessecantes } \\
\hline & Testemunha & Carfentrazone & Glufosinato de amônio & Paraquat \\
\hline CD $2585 \mathrm{RR}$ & A $16,7 \mathrm{c}$ & A $17,1 \mathrm{c}$ & A $15,9 \mathrm{c}$ & A $16,3 \mathrm{c}$ \\
\hline NA 5909 RG & A 18,4 b & A $18,3 \mathrm{~b}$ & A $17,5 \mathrm{~b}$ & A 16,8 bc \\
\hline BENSO 1RR & A 18,2 b & A $18,8 \mathrm{~b}$ & B $15,2 \mathrm{c}$ & B $15,9 \mathrm{c}$ \\
\hline SYN 1059 RR & A 18,6 b & A $19,0 \mathrm{~b}$ & A 17,7 b & A $18,0 \mathrm{~b}$ \\
\hline BMX Turbo RR & $\mathrm{AB} 20,4 \mathrm{a}$ & A $21,4 \mathrm{a}$ & A 20,9 a & B 19,7 a \\
\hline
\end{tabular}

Médias seguidas pela mesma letra, maiúscula na linha (antecedida da média) e minúscula na coluna, não diferem entre si pelo teste Tukey, a 5\% de probabilidade de erro.

Fonte: Elaboração dos autores. 
Tabela 6. Massa de 100 sementes (g) de cultivares de soja em função da aplicação de diferentes dessecantes em cada estádio fenológico na safra 2011/12, do município de Campos Novos, SC.

\begin{tabular}{|c|c|c|c|c|}
\hline \multirow{3}{*}{ Cultivares } & \multicolumn{4}{|c|}{ Estádio Fenológico R 7.1} \\
\hline & \multicolumn{4}{|c|}{ Dessecantes } \\
\hline & Testemunha & Glufosinato de amônio & Diquat & Paraquat \\
\hline & \multicolumn{4}{|c|}{  } \\
\hline BENSO 1RR & $\mathrm{AB} 15,2 \mathrm{c}$ & A 16,0 a & $\mathrm{C} 13,4 \mathrm{c}$ & B $14,3 \mathrm{bc}$ \\
\hline NA 5909 RG & A $15,8 \mathrm{~b}$ & A $15,3 \mathrm{ab}$ & A $14,8 \mathrm{ab}$ & A $14,9 \mathrm{ab}$ \\
\hline BMX Turbo RR & A 16,9 a & B $15,6 \mathrm{ab}$ & B 15,5 a & B 15,4 a \\
\hline CD $2585 \mathrm{RR}$ & A $14,8 \mathrm{c}$ & $\mathrm{AB} 14,2 \mathrm{c}$ & $\mathrm{AB} 14,2 \mathrm{bc}$ & B 13,6 c \\
\hline \multirow[t]{2}{*}{ SYN 1059 RR } & A $16,8 \mathrm{a}$ & $\mathrm{B} 14,8 \mathrm{bc}$ & $\mathrm{B} 14,5 \mathrm{~b}$ & B 14,2 bc \\
\hline & \multicolumn{4}{|c|}{ Estádio Fenológico R 7.3} \\
\hline BENSO 1RR & A 15,2 bc & A $15,3 \mathrm{c}$ & A $14,7 \mathrm{c}$ & A $15,5 \mathrm{c}$ \\
\hline NA 5909 RG & A 15,8 b & A $16,0 \mathrm{bc}$ & A $15,5 b$ & A $16,1 \mathrm{bc}$ \\
\hline BMX Turbo RR & A 16,9 a & A 16,9 a & A 16,8 a & A 17,5 a \\
\hline CD 2585 RR & B $14,8 \mathrm{c}$ & A $15,7 b c$ & B $14,4 \mathrm{c}$ & B $14,5 \mathrm{~d}$ \\
\hline SYN 1059 RR & A $16,8 \mathrm{~d}$ & A $16,4 \mathrm{ab}$ & A 16,4 a & A $16,7 \mathrm{ab}$ \\
\hline
\end{tabular}

Médias seguidas pela mesma letra, maiúscula na linha (antecedida da média) e minúscula na coluna, não diferem entre si pelo teste Tukey, a 5\% de probabilidade de erro.

Fonte: Elaboração dos autores.

O percentual de germinação médio foi de 83\% (safra 2011/12), e apresentou interação significativa entre o dessecante e a cultivar, e também do dessecante com estádio de aplicação do produto (Tabela 1). O uso dos dessecantes paraquat e glufosinato de amônio proporcionaram manutenção do percentual de germinação, entre 90 e $89 \%$, respectivamente, estando dentro dos padrões exigidos (BRASIL, 2013) quando comparado com a testemunha, que apresentou apenas $76 \%$ de germinação (Tabela 7). O percentual de germinação foi superior e diferente da testemunha (76\%) para os dessecantes paraquat (92\%) e glufosinato de amônio (90\%) no estádio R7.1 de aplicação do produto.

Tabela 7. Germinação de sementes de cultivares de soja em função da aplicação de diferentes dessecantes na safra 2011/2012, do município de Campos Novos, SC.

\begin{tabular}{|c|c|c|c|c|}
\hline \multirow{3}{*}{ Cultivares } & \multicolumn{4}{|c|}{ Dessecantes } \\
\hline & Testemunha & Carfentrazone & Glufosinato de amônio & Paraquat \\
\hline & & & & ------ \\
\hline CD $2585 \mathrm{RR}$ & B $78 \mathrm{ab}$ & B 83 a & A $91 \mathrm{ab}$ & A 92 a \\
\hline NA 5909 RG & AB 84 a & B $79 \mathrm{ab}$ & A $87 \mathrm{ab}$ & A 89 a \\
\hline BENSO 1RR & B 81 a & C $71 \mathrm{~b}$ & $\mathrm{AB} 86 \mathrm{~b}$ & A 91 a \\
\hline SYN 1059 RR & C $64 \mathrm{c}$ & B $80 \mathrm{ab}$ & A 93 a & A 90 a \\
\hline BMX Turbo RR & B $71 \mathrm{bc}$ & B 74 bc & A $87 \mathrm{ab}$ & A 88 a \\
\hline
\end{tabular}

Médias seguidas pela mesma letra, maiúscula na linha (antecedida da média) e minúscula na coluna, não diferem entre si pelo teste Tukey, a 5\% de probabilidade de erro.

Fonte: Elaboração dos autores. 
Na safra 2012/13 observou-se que as cultivares de soja responderam diferentemente a aplicação dos dessecantes, a cultivar BMX Turbo RR e NA 5909 $\mathrm{RG}$ apresentou maior germinação na testemunha quando comparado aos demais dessecantes. Já as cultivares CD 2585 RR, SYN 1059 RR e Benso $1 R R$ não apresentaram diferença na germinação com ou sem aplicação (Tabela 8).

Tabela 8. Germinação de sementes de cultivares de soja em função da aplicação de diferentes dessecantes na safra 2012/2013, do município de Campos Novos, SC.

\begin{tabular}{|c|c|c|c|c|}
\hline \multirow{2}{*}{ Cultivares } & \multicolumn{4}{|c|}{ Dessecantes } \\
\hline & Testemunha & Glufosinato de amônio & Diquat & Paraquat \\
\hline & & $--\%$ & & \\
\hline CD $2585 \mathrm{RR}$ & A 94 a & A 91 a & A 94 a & A 93 a \\
\hline NA 5909 RG & A 92 a & BC $84 \mathrm{ab}$ & C $81 \mathrm{~b}$ & AB 88 ab \\
\hline BENSO 1RR & A $90 \mathrm{ab}$ & AB $85 a b$ & $\mathrm{~B} 80 \mathrm{~b}$ & B $83 \mathrm{~b}$ \\
\hline SYN 1059 RR & A 84 bc & A 82 b & A $83 \mathrm{~b}$ & A 84 b \\
\hline BMX Turbo RR & A $78 \mathrm{c}$ & A $80 \mathrm{~b}$ & $\mathrm{~A} 80 \mathrm{~b}$ & A $81 \mathrm{~b}$ \\
\hline
\end{tabular}

Médias seguidas pela mesma letra, maiúscula na linha (antecedida da média) e minúscula na coluna, não diferem entre si pelo teste Tukey, a 5\% de probabilidade de erro.

Fonte: Elaboração dos autores.

Na safra 2011/12 a dessecação pré-colheita com o uso de paraquat e glufosinato de amônio no estádio R7.1 antecipou a colheita de todas as cultivares em seis dias. Guimarães et al. (2012) também observaram antecipação da colheita em 4 e 6 dias com uso do glufosinato de amônio e paraquat nos estádios de aplicação R6.0 e R7.2. O fato da antecipação da colheita ter ocorrido com o uso dos dessecantes paraquat e glufosinato de amônio pode estar associado a velocidade de ação destes dessecantes e as condições ambientais no dia da aplicação do produto e na pré-colheita (Figura 1). Sabe-se que o herbicida paraquat assim como o diquat é facilmente absorvido pelas folhas (após 30 minutos de sua aplicação), atua rapidamente na presença de luz, promovendo severa injúria nas folhas (SILVA; SILVA, 2007). O glufosinato de amônio possui ação mais lenta que o paraquat e diquat, porém proporciona clorose e murchamento das folhas de 1 a 3 dias (ROMAN et al., 2007).

A antecipação da colheita proporcionada pelo uso da dessecação em pré-colheita para as cultivares de soja da safra 2011/12 permitiu a manutenção do percentual de germinação das sementes quando comparado à testemunha. Este fato pode estar associado a exposição da testemunha às variações de umidade relativa do ar e temperatura máxima $\left(26^{\circ}\right)$ e mínima $\left(14^{\circ} \mathrm{C}\right)$ ocorridas no local do experimento, entre o período da colheita $1(03 / 04 / 2012)$ e 2 (10/04/2012) (Figura 1). Segundo Ahrens e Peske (1994) o teor de água da semente pode variar em até 5,6\% em função da umidade relativa do ar e da temperatura do ambiente, entre o período da manhã e da tarde em períodos sem chuva. Este processo de absorção e perda de água diária pela semente pode acelerar a deterioração e consequentemente a perda de germinação e vigor das sementes (PESKE; LUCCA FILHO; BARROS, 2006).

$\mathrm{O}$ atraso da colheita é um dos principais fatores de redução da qualidade de sementes de soja a campo, este fato foi relatado por Inoue et al. (2012) que ao analisar diferentes áreas com aplicação de dessecantes pré-colheita evidenciaram que sementes oriundas de plantas não dessecadas apresentaram menor percentual de germinação, devido ao atraso da colheita.

$\mathrm{Na}$ safra 2011/12 observa-se que o herbicida carfentrazone não proporcionou a antecipação 
da colheita das cultivares de soja. O mesmo não foi eficiente no processo de desfolha em função da sua degradação pela cultura da soja, a qual foi comprovado por Dayan et al. (1997). Porém esta seletividade ainda é uma opção de manejo de plantas daninhas, principalmente de dicotiledôneas no final de ciclo da soja, sem comprometer a qualidade e a produtividade de sementes.

Na safra 2012/13 não houve antecipação de colheita com o uso dos dessecantes, independente do estágio de aplicação, o que pode ser explicada pela presença da chuva na pré-colheita o que não proporcionou uma redução no teor de água da semente antecipadamente, com relação a testemunha. Isto ocorreu, pois o teor de água das sementes de soja na pré-colheita entra em equilíbrio com o ambiente, o que fez com que as sementes permanecessem com alto teor de umidade devido a presença de chuvas no período de 28/02/2013 a 21/03/2013 (Figura 1). Lacerda et al. (2001) verificaram que a dessecação com paraquat, diquat, glufosinato de amônio e a mistura de diquat + paraquat não proporcionou antecipação na colheita da soja em função da presença de chuvas esparsas e temperaturas elevadas no final do ciclo da cultura.

Desta forma, observou-se que a dessecação précolheita no estádio R7.1 com uso dos dessecantes glufosinato de amônio e paraquat antecipou a colheita das cultivares de soja, não influenciou negativamente a produtividade de sementes, os componentes de produção e a germinação de sementes, o que permite indicar esta técnica como uma alternativa para antecipar a colheita em áreas de produção de sementes no meio oeste catarinense.

\section{Conclusões}

A dessecação em pré-colheita nas duas safras agrícolas promoveu a manutenção da produtividade e do percentual de germinação de sementes da maioria das cultivares de soja.

Em condições de ausência de chuva em pré- colheita, recomenda-se o uso dos dessecantes glufosinato de amônio e paraquat no estádio 7.1 como uma alternativa para antecipar a colheita nos campos de produção de sementes de soja.

\section{Agradecimentos}

A cooperativa Coaccer, Copercampos e Epagri pela disponibilidade de área e maquinário e a empresa FMC pela doação do herbicida Aurora.

A bolsa concedida ao primeiro autor pelo programa FUMDES da secretaria de educação de Santa Catarina e a UNOESC pela liberação parcial para o desenvolvimento do experimento.

Ao CNPQ (Conselho Nacional de Desenvolvimento Cientifico e Tecnológico) pelo apoio financeiro ao projeto.

\section{Referências}

AHRENS, D. C.; PESKE, S. T. Flutuações de umidade e qualidade de semente de soja após a maturação fisiológica. II. Avaliação da qualidade fisiológica. Revista Brasileira de Sementes, Londrina, v. 16, n. 2, p. 111-115, 1994.

ASSOCIAÇÃO DE PRODUTORES DE SEMENTES E MUDAS DO ESTADO DE SANTA CATARINA APROSESC. Dados de produção de sementes de soja. Disponível em: <aprosesc@gmail.com>. Acesso em: 5 dez. 2014.

BRASIL. Ministério da Agricultura, Pecuária e Abastecimento. Instrução Normativa $n^{\circ} 45$ de 17 de dezembro de 2013. Ministério da Agricultura, Pecuária e Abastecimento. Secretaria de Defesa Agropecuária. Brasília, 2013. Mapa/ACS, 38 p.

Ministério da Agricultura, Pecuária e Abastecimento. Regras para análise de sementes. Ministério da Agricultura, Pecuária e Abastecimento. Secretaria de Defesa Agropecuária. Brasília, 2009. Mapa/ACS, $395 \mathrm{p}$.

CORRÊA, C. Dessecação química em pré-colheita de plantas de soja: rendimento e qualidade de sementes. 2012. Dissertação (Mestrado em Produção Vegetal) Universidade do Estado de Santa Catarina, Lages.

DALCHIAVON, F. C.; CARVALHO, M. P. Correlação linear e espacial dos componentes de produção e 
produtividade da soja. Semina: Ciências Agrárias, Londrina, v. 33, n. 2, p. 541-552, 2012.

DALTRO, E. M. F.; ALBUQUERQUE, M. C. F.; FRANÇANETO, J.B. GUIMARÃES, S. C.; GAZZIERO, D. L. P.; HENNING, A. A. Aplicação de dessecantes em pré-colheita: efeito na qualidade fisiológica de sementes de soja. Revista Brasileira de Sementes, Londrina, v. 32, n. 1, p. 111-122, 2010.

DAYAN, F. E.; DUKE, S. O.; WEETE, J. P.; HANCOCK, H. G. selectivity and mode of action of carfentrazone, a novel phenyl triazolinone herbicide. Pest Management Science, Stoneville, v. 51, n. 1, p. 65-73, 1997.

DUFLOTH, J. H.; CORTINA, N.; VEIGA, M.; MIOR, L. C. Estudos básicos regionais de Santa Catarina. Florianópolis: Epagri, 2005. 101 p.

EMPRESA DE PESQUISA AGROPECUÁRIA E EXTENSÃO RURAL DE SANTA CATARINA/ CENTRO DE INFORMAÇÕES DE RECURSOS AMBIENTAIS E DE HIDROMETEOROLOGIA EPAGRI/CIRAM. Monitoramento meteorológico. Florianópolis: Epagri, 2013. Disponível em: <http:// ciram.epagri.sc.gov.br/>. Acesso em: 14 ago. 2013.

FRANÇA NETO, J. B.; KRZYZANOWSKI, F. C.; PÁDUA, G. P.; COSTA, N. P.; HENNING, A. A. Tecnologia da produção de sementes de soja de alta qualidade - Série Sementes. Londrina: EMBRAPA/Soja, 2007. 12 p.

GUIMARÃES, V. F.; HOLLMANN, M. J.; FIOREZE, S. L.; ECHER, M. M.; RODRIGUES-COSTA, A. C. P.; ANDREOTTI, M. Produtividade e qualidade de sementes de soja em função de estádios de dessecação e herbicidas. Planta Daninha, Viçosa, MG, v. 30, n. 3, p. 567-573, 2012.

INOUE, M. H.; JÚNIOR MARCHIORI, O.; BRACCINI, A. L.; OLIVEIRA JÚNIOR, R. S.; ÁVILA, M. R.; COSTANTINI, J. Rendimento de grãos e qualidade de sementes de soja após a aplicação de herbicidas dessecantes. Ciência Rural, Santa Maria, v. 1, n. 1, p. 71-83, 2003.

INOUE, M. H.; PEREIRA, P. S. X.; MENDES, K. F.; BEM, R.; DALLACORT, R.; MAINARDI, J. T.; ARAÚJO, D. V.; CONCIANI, P. A. Determinação do estádio de dessecação em soja de hábito indeterminado no Mato Grosso. Revista Brasileira de Herbicidas, Santa Maria, v. 33, n. 4, p. 769-770, 2012.

LACERDA, A. L. S.; LAZARINI, E.; SÁ, M. E.; WALTER FILHO, V. V. Aplicação de dessecantes na cultura da soja: antecipação da colheita e produção de sementes. Planta Daninha, Viçosa, MG, v. 19, n. 3, p. 381-390, 2001.
LAMEGO, F. P.; GALLON, M.; BASSO, C. J.; KULCZYNSKI, S. M.; RUCHEL, Q.; KASPARY, T. E.; SANTI, A. L. Dessecação pré colheita e efeitos sobre a produtividade e qualidade fisiológica de sementes. Planta Daninha, Viçosa, MG, v. 31, n. 1, p. 929-938, 2013.

MARCOS FILHO, J. Fisiologia de sementes de plantas cultivadas. Piracicaba: FEALQ, 2005. 495 p.

MUNDSTOCK, C. M.; THOMAS, A. L. Soja fatores que afetam o crescimento e o rendimento de grãos. Porto Alegre: Evangraf, 2005. 31 p.

PELÚZIO, J. M.; RAMO, L. M.; FIDELIS, R. R.; AFFÉRRI, F. S.; CASTRO NETO, M. D.; CORREIA, M. A. R. Influência da dessecação química e retardamento de colheita na qualidade fisiológica de sementes de soja no sul do estado do Tocantins. Bioscience Journal, Uberlândia, v. 24, n. 2, p. 77-82. 2008.

PEREIRA, T.; COELHO, C. M. M.; BOGO, A.; GUIDOLIN, A. F.; MIQUELUTTI, D. J. Diversity in common bean landraces from south Brazil. Acta Botanica Croatica, Rooseveltov, v. 68, n. 1, p. 79-92, 2009.

PESKE, S. T.; LUCCA FILHO, O. A.; BARROS, A. C. S. A. Sementes: fundamentos científicos e tecnológicos. Pelotas: UFPel, 2006. 545 p.

RITCHIE, S. W.; HANWAY, J. J.; THOMPSON, H. E. How a soybean plant develops. Ames: Iowa State University of Science and Technology Cooperative Extension Service. 1982. 20 p.

ROMAN, E. S.; BECKIE, H.; VARGAS, L.; HALL, L.; RIZZARDI, M. A.; WOLF, T. M. Como funcionam os herbicidas: da biologia a aplicação. Passo Fundo: Berthier, 2007. 159 p.

SANTOS, E. R.; BARROS, A. B.; CAPONE, A.; MELO, A. V.; CELLA, A. J. S.; SANTOS, W. R. Divergência genética entre genótipos de soja com base na qualidade de sementes. Revista Brasileira de Ciências Agrárias, Recife, v. 7, n. 2, p. 247-254, 2012.

SEDYAMA, T. Tecnologia e produção de sementes de soja. Londrina: Mecenas, 2013. 352 p.

SILVA, A. A.; SILVA, J. F. Tópicos em manejo de plantas daninhas. Viçosa: UFPel, 2007. 367 p.

SOUZA, C. A.; GAVA, F.; CASA, R. T.; BOLZAN, J. M.; KUHNEM JUNIOR, P. R. Relação entre a densidade de plantas e genótipos de soja Roundup Ready. Planta Daninha, Viçosa, MG, v. 28, n. 4, p. 887-896, 2010.

TOLEDO, M. Z.; CAVARIANI, C.; FRANÇA-NETO, J. B. Qualidade fisiológica de sementes de soja colhidas em duas épocas após dessecação com glifosato. Revista Brasileira de Sementes, Londrina, v. 34, n. 1, p. 134-142, 2012. 